\title{
Aspectos emocionais e cognitivos do usuário na interação com a informação: um estudo de caso no Laboratório de Inovações Tecnológicas para Ambientes de Experiência (ITAE)
}

Ivette Kafure

\author{
Coordenadora do Grupo de Pesquisa Fatores \\ Humanos na Interação e Comunicação da \\ Informação FHICI/FCI/UnB
}

Jorge Luís Barreto Pereira

\begin{abstract}
Coordenador do Laboratório de Inovações Tecnológicas para Ambientes de Experiência ITAE/CDT/UnB
\end{abstract}

http://dx.doi.org/10.1590/1981-5344/2546

É uma experiência realizada no Laboratório de Inovações Tecnológicas para Ambientes de Experiência (ITAE) com estudantes de disciplinas do grupo de pesquisa Fatores Humanos na Interação e Comunicação da Informação (FHICI), do Programa de Pós-Graduação da Faculdade de Ciência da Informação (FCI) da Universidade de Brasília (UnB). O objetivo principal deste estudo é identificar a percepção dos aspectos emocionais e cognitivos do usuário na interação com a informação. Tem uma abordagem qualitativa na qual é realizada uma experiência que consiste na interação dos participantes com um jogo chamado JogoItae. A metodologia consiste de um caso de estudo onde os alunos da disciplina Design Centrado no Usuário da Informação (DCUI) são submetidos a uma experiência sem qualquer explanação ou conhecimento prévio do que se trata. E na disciplina Fator Emocional na Interação entre o Usuário $e$ a Informação (FEIUI) os alunos foram submetidos à mesma experiência, mas tendo antes todas as explicações necessárias, sendo contextualizados antes do jogo começar. Os resultados indicam que as turmas de estudantes, que não receberam explicações prévias, tiveram algumas vezes uma percepção equivocada do jogo. Nessas turmas, quase todos os estudantes 
demostraram muito desconforto percebendo de forma clara como o usuário se sente diante de um sistema que Ihe foi imposto sem diálogo. As turmas que tiveram todas as explicações necessárias antes do jogo, já não apresentaram sugestões de mudanças, apenas relatando aspectos agradáveis em relação à experiência e uma abertura aos aspectos cognitivos. A conclusão é que os estudantes de ambas as disciplinas adquiriram uma maior percepção e sensibilização quanto à relevância $e$ necessidade de diminuir a distância existente entre a representação cognitiva, o fator emocional e a representação computacional na comunicação e mediação entre o usuário e a informação.

Palavras-chave: Usuário; Experiência; Interação; Comunicação e Mediação da Informação.

\section{Emotional and cognitive aspects of human information interaction: a case study in the Innovation Technological Laboratory for Experience Environment} (ITAE)

It is an experience at the Technological Innovation Laboratory of Environments of Experience (ITAE) at the University of Brasilia (UnB) with the disciplines of the Research Group of Human Factors in the Interaction and Communication of Information (FHICI). The main objective of this study is to identify the perception of user's emotional factor in the Emotional Factor discipline. And the user's cognitive aspects of interaction with information in the discipline of User Centered Design. It is a qualitative approach. There is an interaction and an environment experience with the participants with a game called JogoItae. Uses a case study as a method to capture the experiences of students in an unfamiliar context, in carrying out a task for the first time, without any explanation or prior knowledge; semi-participant observation, interviews, questionnaires and focus group as collection techniques; the interview guides, electronic questionnaires and paper and diary as instruments. After the experience many suggestions were given from the 
students who didn't receive explanations before the game to the change of the game, these students had a clear manifestation of negative perception. But, FHICI's students of the disciplines, who received all the necessary explanations before the game, no longer had suggestions for changes, just reporting enjoyable aspects regarding the experience and an open mind to the cognitive aspects. The results illustrate that the experiment conducted strengthened the content of disciplines. Students have gained greater insight into the relevance of emotional and cognitive aspects of user communication and mediation with the information; and greater awareness on the need to reduce the gap between the cognitive representation, the emotional factor, and the computational representation.

Keywords: User; Experience; Interaction; Mediation; Information Communication.

Recebido em 06.09.2015 Aceito em 23.05.2016

\section{Introdução}

A informação é conceituada como conhecimento registrado em forma escrita, impressa, digital, oral ou audiovisual, em um suporte (LE COADIC, 2004, p. 4). Podendo-se contextualizar os jogos eletrônicos (game ou jogo digital), como artefatos midiáticos potencializadores de informações lúdicas (SOUZA, 2014). O termo lúdico é oriundo de ludus, palavra que tem origem do latim e que significa jogo, brincadeira, divertimento. "O ato lúdico representa um primeiro nível de construção do conhecimento, o nível do pensamento intuitivo" (RODRIGUES; KAFURE, 2013, p. 25). Segundo Bazílio e Soares (2005), a atividade lúdica é uma ação que gera o mínimo de divertimento (LAMEIRA; KAFURE, 2013). Nesse contexto, este estudo ilustra a relação existente entre o indivíduo e seu contexto na interação com a informação, em uma vivência no Laboratório de Inovações Tecnológicas para Ambientes de Experiência (ITAE), em que o conhecimento pode ser agregado de maneira divertida.

É uma proposta interdisciplinar, que incorpora contribuições da fenomenologia para mostrar, explicitar a própria experiência dos participantes na interação com um jogo chamado JogoItae no ITAE, na busca da consciência do usuário por meio da expressão de suas próprias experiências internas. Para a fenomenologia, um objeto, uma sensação, uma recordação, enfim, tudo tem que ser estudado tal como é para o sujeito (CAPALBO, 2008). Trata-se de sensibilizar a consciência dos 
participantes sobre a importância dos aspectos emocionais e cognitivos na interação, comunicação e mediação da informação entre o usuário e a tarefa num contexto determinado. Uma interação e mediação da informação satisfatória é o resultado de um processo gradual e evolutivo, que necessita de ajustes para se adaptar, constantemente, aos seus usuários. Considerar o usuário como uma "caixa preta", sem estudar as funcionalidades internas e emocionais de sua mente, examinar só as manifestações externas e visíveis de sua entidade mental seria negar a responsabilidade social da Ciência da Informação.

A abordagem tradicional coloca a informação objetiva e externa existindo fora do indivíduo. A mensagem é informativa no sentido em que reduz ambiguidade, ao reduzir o número de mensagens alternativas que poderiam ser enviadas. A mediação da mensagem é por um canal, um instrumento. O usuário participa, muitas vezes de maneira passiva, na interação com o sistema de informação. Isto é, é ignorada a possibilidade de criar sua própria realidade, bem como a utilização de seus próprios estoques internos de informação, que poderiam ser usados para compreender as informações externas e as diferentes situações nas quais os indivíduos se encontram. O conhecimento não é absoluto, as pessoas mudam e a mensagem recebida não é necessariamente igual à enviada (DERVIN, 1976; MORRIS, 1994; FERREIRA, 1995).

$O$ ser humano interage com a informação em circunstâncias diversas. Facilitar o acesso à informação por meio de um suporte material é uma parte do caminho. É necessário lançar uma ponte sobre o fosso que separa a ciência (o universo da objetividade) da experiência humana (o domínio da subjetividade), para que haja compatibilidade entre o suporte da informação e o modelo mental que os usuários possuem da tarefa. 0 modelo mental compreende tanto as necessidades de busca, acesso e uso da informação, como as expectativas de uso, localização da informação procurada, aprendizagem rápida e fácil da interface na mediação da informação. E também a coincidência entre a informação que se pretende transferir, por meio do suporte material, e a capacidade de absorção dos usuários que vão decodificar a mensagem, visando uma ótima comunicação na interação entre o usuário e a informação.

A necessidade de comunicação leva o ser humano a estabelecer o diálogo, e a interação de uns com outros pode resultar em aprendizado. Figueiredo (1999, p. 79) ressalta os diversos canais de comunicação que se abrem entre os sistemas de informação e a comunidade a qual eles servem. Empregando a ludicidade, o usuário pode desenvolver suas habilidades simbólicas. Os jogos podem ser ferramentas importantes para a construção de valores, de pensamento crítico e de raciocínio rápido. Para Dalbosco (2007, p. 68), "o diálogo é constitutivo da ação humana e tudo o que produzimos e significamos, culturalmente, brota desta nossa capacidade de dialogar com os outros e de ouvi-los". 
Nesta pesquisa é realizada uma experiência, na que os alunos, indistintamente de suas competências em tecnologia de informação, têm tido oportunidade de colocar-se no lugar de usuários com pouco ou nenhum conhecimento sobre a tarefa a ser realizada, para resolver questões relacionadas ao conteúdo de disciplinas centradas em aspectos cognitivos e emocionais do usuário. A vivência explicita a necessidade de troca de informações entre os alunos na busca de estabelecer estratégias mediadas na interação com o JogoItae no ITAE. Pádua explica que "a necessidade de conhecimento do objeto pelo sujeito, leva-o a executar desde simples ações até operações sobre o objeto" (PÁDUA, 2009, p. 34). $\mathrm{Na}$ interação entre sujeitos ou entre o sujeito e o objeto é que será produzido o conhecimento (KAFURE et al., 2013; RAUPP; GRANDO, 2010).

Serão apresentados com mais detalhes na seção, a seguir, sobre as necessidades e expectativas do usuário da informação. Em seguida, uma seção sobre os aspectos emocionais e cognitivos do usuário antes do relato detalhado da experiência com o JogoItae e as considerações finais.

\section{Necessidades e expectativas do usuário da informação}

Ciência da Informação está relacionada com a representação da informação, tanto em sistemas naturais como em artificiais, no uso de códigos para transmissão eficiente de mensagens e no estudo de dispositivos e técnicas para o processamento da informação, tais como os computadores e os sistemas de informação (BORKO, 1968).

Anteriormente, a interação entre os seres humanos e o suporte na mediação da informação era passiva. Atualmente, cada elemento no suporte, e especificamente na sua interface, pode ser modificado, uma vez transferido à linguagem digital. A interface transforma-se em "informação" e toda a informação pode ser manipulada. Neste tipo de interface destaca-se, dominantemente, a relação signo-significado, ou seja, ela se mostra em função daquilo que convencionalmente representa, isto é, a tarefa. Neste caso, a figura do usuário torna-se determinante na construção dos significados a serem produzidos na comunicação de mediação da informação.

A usabilidade e o fator emocional se perfilam como áreas de pesquisa específicas no estudo de modelos de interfaces e comunicação esperados pelos usuários. É de relevância levar em consideração o usuário, desde as primeiras etapas da concepção da interface, para uma interação e mediação da informação, mais coincidente com as necessidades e expectativas do usuário.

Esta pesquisa procura indagar, aprender, divulgar e verificar se existe uma discrepância entre o modelo mental dos usuários e a atividade (Quadro 1), para contribuir, com a inclusão da objetividade da tarefa, a subjetividade e o fator emocional dos usuários, na geração e aplicação de recomendações para que a interface seja um suporte para: 
a) abusca, acesso e uso da informação;

b)a compreensão de elementos visuais e verbais;

c)a facilidade e satisfação de uso, por meio de elementos visuais e verbais dentro de cada tela do ambiente de interação.

Quadro 1 - Modelo Mental

\begin{tabular}{l|l}
\hline \multicolumn{2}{c}{ Modelo Mental } \\
\hline \hline Necessidades & - busca de informação; \\
& - acesso à informação; \\
& - uso da informação; \\
\hline \multirow{2}{*}{ Expectativas } & - uso fácil da interface na mediação da informação; \\
& - localizar rapidamente a informação procurada; \\
& - aprendizagem fácil da interface na mediação da \\
& - satisfação; na interação, comunicação e mediação da \\
& informação.
\end{tabular}

Fonte: Adaptado de KAFURE (2004, p. 4).

Deve-se levar em conta não apenas a objetividade, mas também a subjetividade dos usuários, que havia sido preterida pelos modelos teóricos representacionistas de ciência cognitiva: "em minha prática, surpreendo-me muitas vezes ao constatar que os seres humanos são quase incapazes de compreender um ponto de vista que não seja o seu próprio, e admitir a sua validade" (CARL GUSTAV JUNG, $1962^{1}$ apud ARNHEIM, 1989, p. 329). Mas, muitas vezes, um sistema de informação é conhecido pelo usuário quando já está em funcionamento, sem um estudo prévio centrado no ser humano e seu modo de ver, interpretar e conviver com o entorno. Isto pode gerar uma discrepância entre as necessidades e expectativas do usuário e as dificuldades encontradas por ele para acessar a informação (NORMAN, 1983; KAFURE, 2004).

$\mathrm{Na}$ explosão de tipos de meios de comunicação, no século $\mathrm{XX}$, e nas atividades realizadas em múltiplos níveis de complexidade, existem diferentes tipos de usuários, necessidades e ritmos diversos "surgem, cada vez mais, novas formas de ser, agir e pensar dos próprios indivíduos sociais e seus grupos, instituições, quaisquer camadas sociais às quais pertençam, o que constitui, por sua vez, as diversas redes da Era da informação" (COSTA; RAMALHO, 2010). Por exemplo, usuários que foram se adaptando às novas tecnologias, acompanhando as mudanças na cultura e os nascidos concomitantemente ao aparecimento do computador pessoal - muitos deles, imersos em um mundo digital, de interação com a máquina e se adaptando às suas evoluções. Os estudos de usuários ressaltam os diversos canais de comunicação que se abrem entre os

\footnotetext{
${ }^{1}$ JUNG, C. G. Psychologische Typen. Zurique: Rascher, 1921. Ingl: Psyshological Types. Nova Iorque: Pantheon, 1962.
} 
sistemas de informação e a comunidade a que eles servem (MOURA, 2010; FIGUEIREDO, 1999; KAFURE et al., 2013; ROCHA; KAFURE, 2015; CUNHA; AMARAL; DANTAS, 2015).

A incorporação das novas tecnologias no desenvolvimento de interfaces para mediação da informação propõe a inter-relação entre diversas áreas, para o estudo dos usuários, a tarefa e atividade. Levando em consideração as necessidades e expectativas dos seres humanos, pois cada área propõe métodos, técnicas e aspectos específicos, no aumento da usabilidade e fator emocional.

\section{Aspectos emocionais e cognitivos do usuário}

A concepção interdisciplinar da interface centrada nos usuários converge com a definição de Löbach (2001), ao afirmar que o desenho é o processo de adaptação do entorno objetual às necessidades físicas e psíquicas dos indivíduos. Em relação ao fator emocional da interface, este trabalho aborda um enfoque ligado ao conceito de usabilidade e aos três aspectos do design sugeridos por Norman (2004): o design visceral, o design comportamental e o design reflexivo. O design visceral diz respeito aos aspectos físicos e ao primeiro impacto causado por um produto. 0 design comportamental diz respeito ao uso sob o ponto de vista objetivo e se refere à função que o produto desempenha. O design reflexivo diz respeito ao uso sob o ponto de vista subjetivo; refere-se à interpretação, compreensão e raciocínio.

Para se ter sucesso na tomada de decisões, afirmava-se, tradicionalmente, que era necessário evitar a intervenção das emoções. Era frequente dissociar a emoção da razão em termos mentais e neurológicos. Hoje, estudos científicos ilustram como a emoção e a cognição são absolutamente entrelaçadas e, também, esclarecem que a emoção auxilia na escolha entre diversas opções e possibilidades em complemento com o conhecimento e a razão (DAMÁSIO, 1994; 2005). De acordo com Cañada (2005), está demonstrado que a percepção sobre um objeto muda, dependendo se ele é fácil de usar ou não, pois, segundo esse autor, nunca desenvolvemos vínculos emocionais positivos com algo cujo uso seja trabalhoso. Desta maneira, a relação entre emoção e usabilidade é direta.

Janczura (1999), em pesquisas de psicologia cognitiva, esclarece que os usuários da informação possuem diferenças que merecem ser estudadas com a finalidade de criar recursos eletrônicos e mecanismos para acessar a informação mais adaptados ao estilo de cada um, concluindo que:

a)diferentes indivíduos procuram e processam a informação utilizando diferentes estratégias;

b)diferentes estratégias podem ser mais ou menos efetivas para diferentes pessoas, em diferentes contextos; 
c)os indivíduos, em alguma medida, podem adotar consistentemente uma ou outra estratégia de processamento da informação (tais tendências são chamadas de estilos).

Na realização de experiências para avaliar a usabilidade, seja de uma interface, de um projeto de interfaces ou prototipagens em papel com a participação de usuários, profissionais da informação e analistas pode ser identificada a existência de uma discrepância entre o modelo mental dos usuários e o modelo conceitual dos profissionais da informação e analistas. Dita discrepância diminuiu quando estabelecido um diálogo entre esses indivíduos, num processo de regulação interativo, por meio de técnicas, tais como a observação, os grupos focais, as entrevistas, a análise da tarefa e a atividade. O processo de regulação pode ser decomposto em criações parciais, interpondo juízos, atos de aceitação ou rejeição, para enriquecer o processo criativo da interface (KAFURE, 2004).

Se a informação existe para servir aos usuários, é primordial aumentar sua relação com a usabilidade e o fator emocional, num processo contínuo, para permitir que os usuários possam gerir a informação de maneira eficaz, eficiente e agradável.

A recuperação da informação depende, entre outros, da subjetividade e do ambiente envolvidos. Trata-se do estudo da experiência de usuário, de sua interação na comunicação e mediação da informação. É um estudo exploratório, descritivo de abordagem qualitativa, e em casos específicos, quali-quantitativa. Utilizam-se, dependendo do contexto, diferentes métodos, como o levantamento e o estudo de caso; técnicas de coleta, como a observação semi-participante; entrevistas, questionários e o grupo focal; instrumentos de coleta, como os guias de entrevista, os questionários eletrônicos e em papel e diário de campo; e técnicas de análise, como estatística descritiva, análise de conteúdo, categorização e interpretação de dados.

\section{A experiência com o JogoItae}

O Laboratório de Inovações Tecnológicas para Ambientes de Experiência (ITAE) é um ambiente de capacitação por meio de simulações da realidade baseado nos princípios da economia da experiência. A economia da experiência, uma teoria desenvolvida em 1999 por B. Josehp Pine e James H. Gilmore. De acordo com estes pesquisadores, não vivemos mais na economia agrária, nem industrial, nem de serviços, mas sim, na economia da experiência, que proporciona experiência para o cliente. $\mathrm{Na}$ economia da experiência, o nível de experiência de entretenimento é o de menor envolvimento; por exemplo, assistir televisão de maneira passiva, na recepção de informações. Ao passo que o nível de aventura exige um maior compromisso por parte do usuário - por exemplo, entrar no ITAE e interagir com o JogoItae. Aplicado à educação 
procura-se ter um ambiente de imersão onde as pessoas participam da experiência. As experiências podem ser diversas (PINE; GILMORE, 1999). Como Ambiente de Experiência, o ITAE se baseia em quatro pilares: educação, imersão, entretenimento e estética. Conforme os princípios da Economia da Experiência o aprendizado é mais efetivo se envolvermos ao máximo os sentidos, em um ambiente agradável e divertido.

Para explicitar mais sobre a economia da experiência, pode ser feita uma comparação com uma festa de aniversário. Na economia agrária, no início, as pessoas iam ao quintal para coletar algumas coisas para fazer a festa. Na economia industrial a pessoa comprava no mercado os ingredientes para fazer a festa. Na economia de serviço seria encomendado um bolo, os salgadinhos e os doces. Ao passo que, na economia da experiência, é encomendada a festa, os palhaços e os enfeites. O propósito é proporcionar um momento agradável, marcante e inesquecível.

O ITAE está dotado de um sistema hipermídia, que permite o intercâmbio de informação por diversos meios, tais como textos, vídeos, sons e animações, para promover a interação e a aprendizagem (Figura 1). O ITAE pertence ao Centro de Apoio ao Desenvolvimento Tecnológico da Universidade de Brasília (CDT/UnB) e pode ser contratado para agregar valor a qualquer curso, trabalhando a motivação, o comportamento e reforçando a assimilação do conteúdo programático (ITAE/CDT/UnB, 2011b). No caso das disciplinas Design Centrado no Usuário da Informação (DCUI) e Fator Emocional na Interação entre o Usuário e a Informação (FEIUI), que têm reunido estudantes e profissionais de diversas áreas, tais como ciência da informação, administração, educação, arquivologia, biblioteconomia, informática, comunicação, computação, ciência política, design, psicologia, marketing, filosofia, ciências contábeis e engenharia, contou-se com o ambiente lúdico no ITAE em que os estudantes ficaram imersos. Tendo-se trabalhado com os sentidos dos estudantes.

Figura 1 - Laboratório de Inovações Tecnológicas para Ambientes de Experiência 


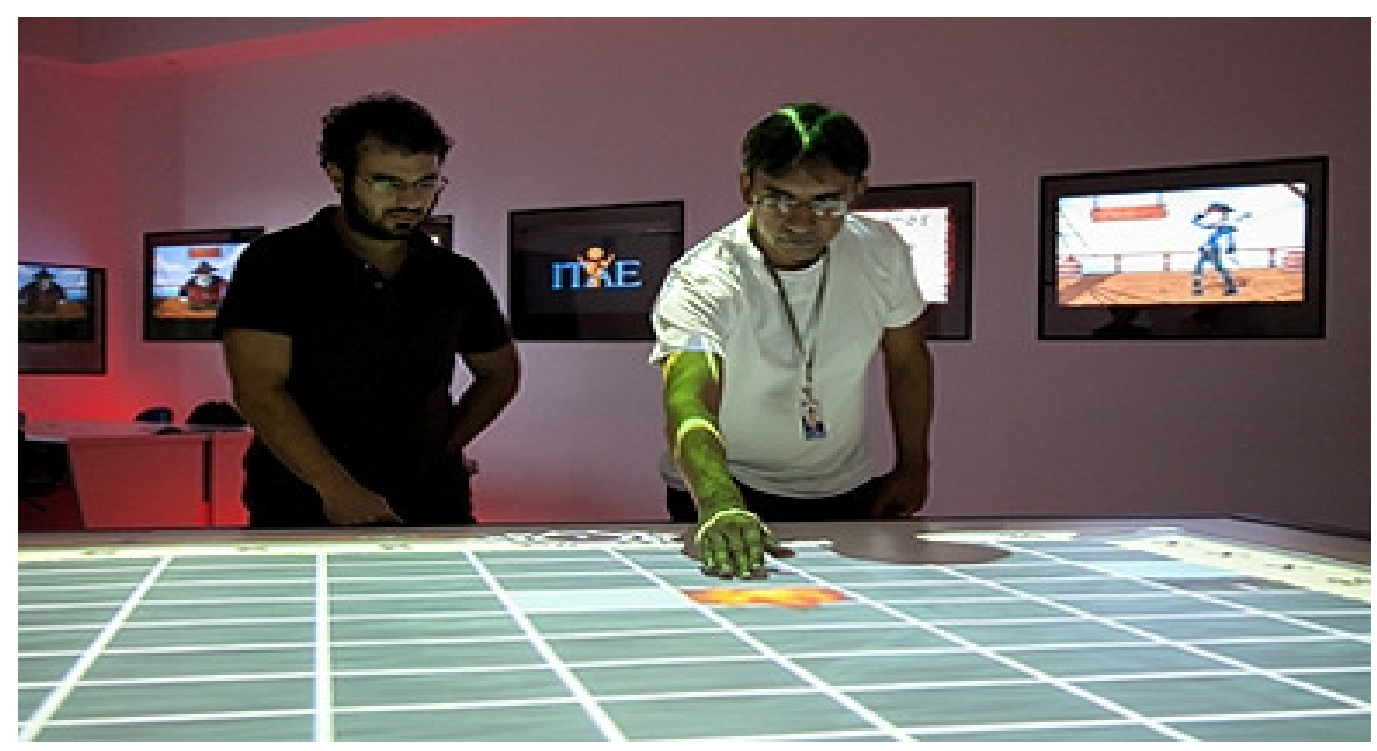

Fonte: ITAE/CDT/UnB (2011a).

As experiências no ITAE têm criado valor agregado ao conteúdo das disciplinas do Grupo FHICI, na medida em que tem auxiliado em uma maior compreensão, atenção e interesse personalizados, no estudo dos usuários da informação, por parte dos estudantes. A finalidade última dos sistemas de informação é mediar a realização da tarefa, dessa maneira é preciso conhecer o usuário e contar com sua participação. A subjetividade "não ambiciona enquadrar o sujeito em uma categoria teórica explicativa, mas aprender de sua singularidade" (TACCA; REY, 2008, n.p.). Para inferir o comportamento dos usuários na sua interação com os sistemas de informação, é fundamental saber suas necessidades de informação, de domínio afetivo; onde e como eles vão encontrar informação, de domínio cognitivo; e a execução de seus caminhos físicos, de domínio psicomotor (DERVIN, 1996; BAX; DIAS, 1997; RAMOS et al., 2000; HAAN, 2000; KAFURE, 2004).

\subsection{A experiência com o Jogortae nas disciplinas do Grupo de Pesquisa FHICI}

A experiência com as turmas da disciplina DCUI tiveram início na sala de aula da FCI. Para começar, foram fornecidas poucas informações sobre a tarefa a ser realizada no ITAE/CDT. Em todas as turmas, a maioria dos participantes têm desconhecido a existência e localização do ITAE. No caso dessa pesquisa, os estudantes precisam tomar decisões, muitas vezes sem nenhum tipo de conhecimento prévio. Os discentes normalmente têm duvidado sobre o caminho para chegar ao ITAE; alguns tem se perdido, mas com suas competências pessoais e/ou intercâmbio de informações e/ou comunicações chegaram ao destino proposto. 
Quando introduzidos ao laboratório ITAE os participantes entram num ambiente de imersão, que possui controle automatizado de som, luz e projeções por reconhecimento de voz. Escuta-se música de fundo e visualizam-se luzes tênues. O Coordenador saúda os participantes, chama ao laboratório com o nome "ITAE". E o ITAE chama o Coordenador de "Mestre". O dialogo é aberto (Quadro 2).

\section{Mestre: ITAE?}

ITAE: Chamou, mestre?

Mestre: Bom dia.

ITAE: Bom dia. Qual o seu pedido, mestre?

Mestre: Acende tudo.

ITAE: Acendendo.

Mestre: Apaga tudo.

ITAE: Apagando.

Mestre: Acende a luz negra.

ITAE: Acendendo.

Mestre: Acende as luzes vermelhas.

ITAE: Acendendo.

O Mestre chama uma participante para falar com o ITAE, diz para falar alguma coisa.

A participante: Oi.

ITAE: Quem é essa gatinha?

Se escutam risos dos participantes.

Quadro 2 - Diálogo inicial entre o Mestre e o laboratório ITAE Fonte: ITAE (31 out. 2012).

No ITAE, normalmente com a chegada de novos participantes, são fornecidas as explicações necessárias para a compreensão do contexto e do JogoItae. Mas, no caso da da disciplinas DCUI, trata-se de uma experiência na qual os participantes são convidados a se sentir no papel de usuários num ambiente de imersão desconhecido, a ser explorado. Consequentemente, essas explicações são deixadas para depois da experiência.

O JogoItae é previsto para começar em duas mesas interativas. Dependendo da quantidade de alunos, jogam em uma mesa só ou são divididos em dois grupos para jogar nas mesas (Quadro 3). ITAE

Quadro 3 - Diálogo para iniciar o jogo entre o Mestre e o laboratório 


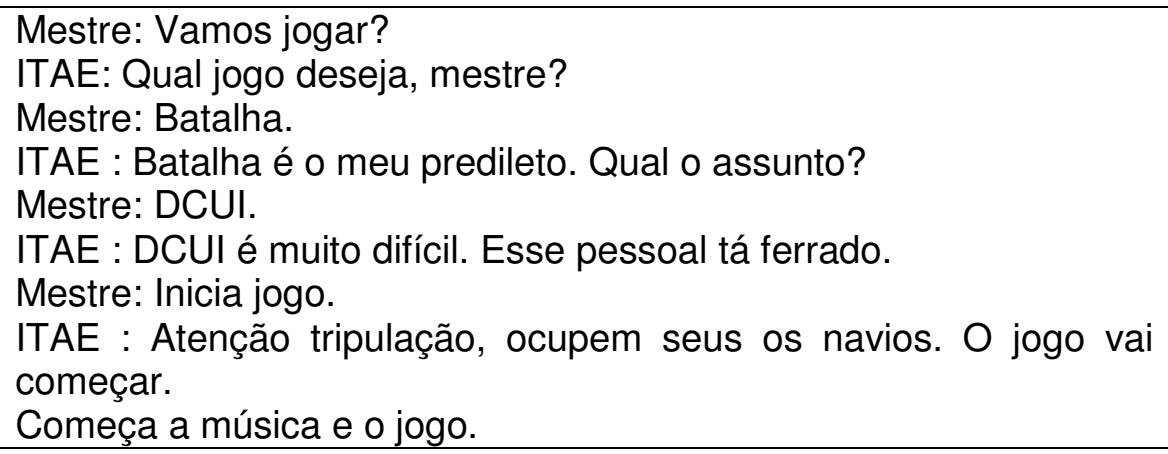

Fonte: ITAE (3 set. 2013).

Os estudantes tiveram que descobrir qual era a intenção do jogo de tipo quiz, com perguntas e respostas, de verdadeiro ou falso, múltipla escolha e associativas. Respondendo às perguntas, pode-se ganhar recursos para entrar no jogo. Quanto mais recursos se obtêm, mais jogadas podem ser feitas. As perguntas podem ser moldadas conforme 0 conteúdo desejado. Os personagens são o Pirata Barba Rala e o Capitão Muralha, em uma versão eletrônica do jogo chamado Batalha Naval. O objetivo principal do jogo é destruir toda a frota inimiga.

Os estudantes interagiram de maneira lúdica, colaborativa e interdisciplinar com um jogo que não conheciam, para se colocar no lugar de usuários que interagem pela primeira vez com um sistema de informação. De acordo com Kishimoto (1996), o ato lúdico representa um primeiro nível de construção do conhecimento, o nível de pensamento intuitivo. O mais difícil, segundo manifestações dos estudantes, foi descobrir como se articulavam as perguntas temáticas, que deveriam ser respondidas durante o jogo, qual a utilidade delas e como ir de uma janela para a outra na interface. Para terminar, foi formada uma roda para discutir a experiência. Nesse momento, os participantes fizeram várias críticas ao jogo sugerindo várias modificações, de acordo com as dificuldades que eles enfrentaram. Percebeu-se que não havia muita diferença entre as dificuldades dos alunos e as encontradas por qualquer usuário da vida real.

Em algumas turmas, da disciplina DCUI, foi proposto para os alunos realizarem os pré-testes de seus projetos utilizando o JogoItae, para a caracterização dos perfis de diferentes tipos de usuários. Esses estudantes manifestaram, entre outras opiniões, que o inovador foi que essa experiência permitiu-Ihes participar de maneira ativa no desenvolvimento dos projetos de seus colegas. Que em outras ocasiões eles tomavam conhecimento dos trabalhos que estavam sendo realizados, mas não interagiram de maneira direta, como vivenciado com a experiência realizada nessa oportunidade no ITAE. 
No ITAE têm expressado que essa experiência, na que os usuários chegam sem explicação nenhuma, é bem diferente comparando a outras experiências, nas que as pessoas contam normalmente com todas as explanações. Quem trabalha no ITAE teve que se concentrar e fazer um esforço para evitar auxiliar aos alunos. Isto, para eles, foi importante e produtivo em relação à compreensão das necessidades e expectativas dos usuários (Quadro 1).

A aplicação do JogoItae nas turmas da disciplina FEIUI só difere da aplicação do JogoItae nas turmas na disciplina DCUI, porque no inicio na sala de aula, eles são questionados em relação ao seu estado de animo, para comparar o mesmo no final da experiência. Por outro lado, no ITAE é realizada uma explicação prévia de todos os detalhes do jogo. Na roda final os estudantes da disciplina FEIUI expressaram que a experiência no ITAE foi muito interessante; que quando abertos a vivenciar o que foi proposto, foi melhor ainda; ficaram surpresos positivamente ao conhecer o ITAE; gostaram muito do ambiente do laboratório. Observou-se uma mudança no estado de ânimo, para um estado mais alegre se comparado antes da experiência. Por outro lado, compararam as dificuldades de interação com as sentidas e encontradas em outras situações, quando utilizaram um sistema de informação, pela primeira vez, e/ou sem suporte nenhum de interação. Interagiram de maneira espontânea, descontraída e divertida, quando despreocupados com os resultados; ou, tensos e ansiosos, quando a necessidade era de produzir soluções rápidas. Em algumas turmas, surgiram líderes que direcionavam as ações do jogo.

Os alunos que tiveram a oportunidade de participar pela segunda vez, numa outra disciplina do grupo de pesquisa FHICI, conseguiram observar outras coisas que passaram despercebidas na primeira; apreciaram a possibilidade de associar o design com a tecnologia; enfatizaram na importância do estudo e o entendimento do usuário para perceber, porque os usuários não conseguiram compreender ou acessar a informação ou design dos instrumentos tecnológicos disponibilizados para eles. Manifestaram que o número de jogadores em cada mesa fazia diferença para eles.

No ITAE as informações quando aplicado o JogoItae são colhidas por meio de relatórios. Sendo manifestado que a participação das turmas das disciplinas do Grupo de Pesquisa FHICI tem ajudado a centrar o desenvolvimento no usuário. Sendo analisadas as reações das pessoas para tornar os jogos mais ergonômicos. Ouvir os comentários das pessoas ao final da experiência tem ajudado a entender melhor os usuários e a abrir a mente para visões diferentes e inusitadas. "A aplicação dos jogos podendo ouvir os usuários e refletir sobre isso agrega um conhecimento muito difícil de adquirir nos livros" (PEREIRA, 2015).

\section{Considerações finais}


Nesta pesquisa é realizada uma experiência no ITAE, com estudantes de disciplinas do grupo de pesquisa FHICI, sendo identificada a percepção de aspectos emocionais e cognitivos do usuário na interação com a informação.

$\mathrm{Na}$ experiência, para a coleta e análise dos dados, tem sido considerados três momentos: antes, durante e depois da realização da tarefa (KAFURE, 2004). É uma experiência na qual os alunos são convidados a se colocarem no lugar do usuário, a sentirem, por eles mesmos, as dificuldades pelas quais os usuários poderiam passar. É um conceito relacionado com a empatia. De acordo com o dicionário Houaiss a empatia é o "processo de identificação em que o indivíduo se coloca no lugar do outro e, com base em suas próprias suposições ou impressões, tenta compreender o comportamento do outro" (HOUAISS; VILLAR, 2004).

Foi visto isso que a experiência permitiu observar os alunos se colocando no lugar do usuário; qual a sua primeira reação; qual o comportamento das turmas que respondiam melhor às perguntas do jogo; se o jogo estaria chegando ou não ao seu objetivo e de que maneira; se os alunos preparavam estratégias ou tentavam adivinhar as respostas; se eram utilizadas ou não as informações de ajuda disponibilizadas no jogo; e, se a pressão do tempo fazia com que eles respondessem de maneira errada.

Os desenvolvedores do JogoItae têm expressado que a experiência auxilia na elaboração de um jogo mais intuitivo. Os resultados confirmaram que apesar do progresso, cuidados, esforço e intencionalidade da equipe de desenvolvimento, para uma boa interação entre o usuário e o jogo, ainda é preciso buscar nos aspectos emocionais e cognitivos do usuário o que pode ser melhorado. E, como aumentar cada vez mais a sua usabilidade e o fator emocional, para diminuir a distância entre a representação cognitiva que os usuários têm da tarefa e a representação computacional (KAFURE, 2004).

\section{Referências}

ARNHEIM, R. Intuição e intelecto na arte. São Paulo: Martins Fontes, 1989.

BAZÍLIO, H. O; SOARES, M. H. F. B. Elaboração de jogos e atividades lúdicas para ensinar o conceito de lei de Lavoisier. In: CONGRESSO DE PESQUISA, ENSINO E EXTENSÃO DA UFG (CONPEEX), 2., 2005, Goiânia. Anais eletrônicos do II Seminário PROLICEN. Goiânia: UFG, 2005. [CDROM]

BAX, M. P.; DIAS, E. W. A abordagem "Construção de Sentido". In: WORKSHOP DA ECA/USP, São Paulo, 1997. Anais... São Paulo: ECA, 1997. 
<http://cuba.eci.ufmg.br/Bax/Disciplinas/UsuInfo/sensema6.html>. Acesso em: 18 mar. 2003.

BORKO, H. Information science: what is it? American Documentation, v. 19, n, 1, p. 3-5, 1968.

CAÑADA, J. Entrevista sobre los paradigmas del diseño. In: CONEJERA, O.; VEGA, K.; VILLARROEL, C. Diseño emocional: definición, metodología y aplicaciones. Santiago de Chile: Universidad Tecnológica Metropolitana, 2005. (Memoria para optar al grado de Licenciado en Artes y Ciencias del

Diseño Industrial).

CAPALBO, C. Fenomenologia e ciências humanas. Aparecida (SP): Ideias \& Letras, 2008.

COSTA, L. F.; RAMALHO, F. A. A usabilidade nos estudos de uso da informação: em cena, usuários e sistemas interativos de informação. Perspectivas em Ciência da Informação, v. 15, n. 1, p. 92-117, 2010. Disponível em: <http://portaldeperiodicos.eci.ufmg.br/index.php/pci/article/view/887/71 3>. Acesso em: 12 ago. 2013.

CUNHA, M. B.; AMARAL, S. A.; DANTAS, E. B. Manual de estudo de usuários da informação. São Paulo: Atlas, 2015.

DALBOSCO, C. A. Pedagogia filosófica: cercanias de um diálogo. São Paulo: Paulinas, 2007.

DAMÁSIO, A. R. Descartes' error: emotion, reason, and the human brain. New York: Grosset/Putnam, 1994.

DAMÁSIO, A. R. Somos esclavos de las emociones y del entorno. Periódico El País, España, 21 de octubre de 2005.

DERVIN, B. Information needs and information seeking: the search for questions behind the research agenda. Research agenda paper for UCLANSF workshop on social aspects of digital libraries, 1996. Disponível em: <http://is.gseis.ucla.edu/research/dl/dervin.html>. Acesso em: 4 ago. 2002.

DERVIN, B. Strategies for dealing with human information needs: information of communication? (Part one of information: an answer for every question? A solution for every problem?). Journal of Broadcasting, v. 20, n. 3, p. 324-333, Summer 1976.

FERREIRA, S. M. S. P. Novos paradigmas e novos usuários de informação. Ciência da Informação, v. 25, n. 2, p. 1-10, 1995.

FIGUEIREDO, N. M. de. Avaliação de coleções e estudo de usuários. Brasília: ABDF, 1999. 
HAAN, G. de. A formal model of competence knowledge for user interface desing. 2000. Tese (Doutorado em Sistemas de Informação e Conhecimento) - Universidade Vrije Universiteit, Amsterdam, Vrije Universiteit, 2000.

HOUAISS, A.; VILLAR, M. de S. Dicionário Houaiss da Língua Portuguesa. Rio de Janeiro: Objetiva, 2004. Disponível em: <http://houaiss.uol.com.br>. Acesso em: 3 set. 2013.

LABORATÓRIO DE INOVAÇÕES TECNOLÓGICAS PARA AMBIENTES DE EXPERIÊNCIA (ITAE). CENTRO DE APOIO AO DESENVOLVIMENTO TECNOLÓGICO DA UNIVERSIDADE DE BRASÍLIA (CDT/UNB). Jogo ITAE. 2011a.

Disponível em:

<http://www.cdt.unb.br/programaseprojetos/itae/jogoitae?menuprincipal=programas-e-projetos\&menu-action=jogo-itae $>$. Acesso em: 4 set. 2012.

LABORATÓRIO DE INOVAÇÕES TECNOLÓGICAS PARA AMBIENTES DE EXPERIÊNCIA (ITAE) DO CENTRO DE APOIO AO DESENVOLVIMENTO TECNOLÓGICO DA UNIVERSIDADE DE BRASÍLIA (CDT/UNB). Inovações tecnológicas para ambientes de experiência. Disponível em: <http://www.cdt.unb.br/programaseprojetos/itae/index>. 2011b. Acesso em: 4 set. 2012.

JANCZURA, G. A. Acessibilidade conceitual em tarefas de categorização e memória. Brasília: Universidade de Brasília; CNPq, 1999.

KAFURE, I. Usabilidade da imagem na recuperação da informação no catálogo público de acesso em linha. 2004. 311f. Tese (Doutorado em Ciência da Informação) - Universidade de Brasília, Brasília, 2004.

KAFURE, I. et al. A terminologia no estudo do usuário da informação. Biblios, n. 51, 2013.

KISHIMOTO, T. M. Froebel e a concepção de jogo infantil. Revista da Faculdade de Educação, [S.I.], v. 22, n. 1, p. 145-167, jan. 1996. Disponível em: <http://www.revistas.usp.br/rfe/article/view/33600>. Acesso em: 7 abr. 2015.

LAMEIRA, A. K. A.; KAFURE, I. Informação lúdica como ferramenta de aprendizado para nativos digitais. 2013. Número de folhas? Monografia (Iniciação Científica) - Universidade de Brasília, Brasília, 2013.

LE COADIC, Y.-F. A ciência da informação. Brasília: Briquet de Lemos/Livros, 2004.

LÖBACH, B. Design industrial: bases para a configuração dos produtos industriais. São Paulo: Edgar Blücher, 2001. 
MORRIS, R. C. T. Toward a user-centered information science. Journal of the American Society for Information Science, v. 45, n.1, jan. 1994.

MOURA, R. Usabilidade infantil: um olhar atento aos nativos digitais. 2010. 44f. Monografia (Bacharelado em Biblioteconomia) - Universidade de Brasília, Brasília, 2010.

NORMAN, D. A. Some observations on mental models. In: GENTNER, D.; STEVENS, A. L. Mental models. Hillsdale, New Jersey: Lawrence Erlbaum Associates, 1983. p. 7-14.

NORMAN, D. A. Emotional design: why we love (or hate) everyday things. New York: Basic Books, 2004.

PÁDUA, G. L. D. de. A epistemologia genética de Jean Piaget. Revista FACEVV, Vila Velha, n. 2, p. 22-35, 1 sem. 2009.

PEREIRA, J. L. B. Entrevista sobre a experiência do usuário no ITAE [26 de maio de 2015]. Entrevistador: I. Kafure. Brasília: Grupo de Pesquisa Fatores Humanos na Interação e Comunicação da Informação. 1 e-mail. Entrevista concedida ao Projeto Comunicação e mediação na interação entre o usuário e a informação, Faculdade de Ciência da Informação, Universidade de Brasília, 2015.

PINE, J.; GILMORE, J. The experience economy. Boston: Harvard Business School Press, 1999.

RAMOS, M. E. M.; BERTHOLINO, M. L. F.; FERREIRA, M. N.; CARVALHO, T. de; FUNARO, V. M. B. O comportamento do usuário na busca de informação automatizada em lina e em CD-ROM. In: Tecnologia e novas formas de gestão em bibliotecas universitárias. Organizado por Maria Etelvina Madalozzo Ramos. Ponta Grossa: Editora UEPG, 1999, p. 157182.

RAUPP, A. D.; GRANDO, N. I. O potencial das interações sociais em situações de jogo no processo ensino-aprendizagem de matemática. In: ENCONTRO DE PESQUISA EM EDUCAÇÃO DA REGIÃO SUL - ANPEDSUL, 8., 2010, Londrina/PR. Anais... Londrina: UEL/ANPED, 2010. v. 1. p. 1-07.

ROCHA, S. F.; KAFURE, I. O fator emocional na interação entre o usuário e a Revista Ibero-Americana de Ciência da Informação - RICI. Revista Ibero-Americana de Ciência da Informação, v. 6, p. 56-70, 2013.

RODRIGUES, V. R.; KAFURE, I. A interação entre a criança da primeira infância e a informação digital. Biblionline (João Pessoa), v. 9, p. 75-95, 2013.

SOUZA, A. Comunicação e mediação da informação no desenvolvimento do jogo eletrônico. 2014. 108f. Dissertação (Mestrado em Programa de 
Pós-Graduação em Ciência da Informação) - Universidade de Brasília, Brasília, 2014.

TACCA, M. C. V. R.; REY, F. L. G. Produção de sentido subjetivo: as singularidades dos alunos no processo de aprender. Psicol. Cienc. Prof., Brasília, v. 28, n. 1, 2008. Disponível em: <http://www.scielo.br/scielo.php?script=sci_arttext\&pid=S141498932008000100011 \&lng=en\&nrm=iso >. Acesso em: 3 abr. 2015. 